\title{
Clinicopathological Features and Surgical Outcomes in Patients Undergoing Radical Resection for Gastric Cancer with Undifferentiated Carcinoma, Neuroendocrine Tumor, and Gastrointestinal Stromal Tumor Histology
}

\author{
(D) Uğur Topal1, (D) Fatih Dal2, (D) Erdoğan Mütevelli Sözüer¹, (D) Muhammet Akyüz², (D Şadi Yenel İsaoğulları², (D) Mustafa Gök2 \\ (D) Kemal Deniz 3 \\ 1 Erciyes University Faculty of Medicine, Department of General Surgery, Division of Surgical Oncology, Kayseri, Turkey \\ 2Erciyes University Faculty of Medicine, Department of General Surgery, Kayseri, Turkey \\ ${ }^{3}$ Erciyes University Faculty of Medicine, Department of Pathology, Kayseri, Turkey
}

\section{Abstract}

Objective: Gastric cancer consists of many histological subtypes. The prognostic value of histological types in stomach cancer is not well defined. In this study, we investigated the effects of different histological types on surgical and oncological outcomes in stomach cancer.

Methods: Patients with a histology of undifferentiated carcinoma, neuroendocrine tumors, and gastrointestinal stromal tumors were included in the study of 1,060 patients who underwent gastrectomy for gastric cancer between 2010 and 2019. They were divided into three groups as group 1 (undifferentiated tumor), group 2 (neuroendocrine tumor), and group 3 (gastrointestinal stromal tumor). Demographic and clinical features, operative and oncological outcomes, and survival were compared between the groups.

Results: Of a sample group that included 1,060 diseases, 53 patients (5\%) were included in the study. Group 1 consisted of 24 patients, group 2 consisted of 10 patients, and group 3 consisted of 19 patients. Average age $(p=0.591)$, was similar across all groups. Tumors were most frequently located in the corpus ( $41.7 \%$ vs. $80 \%$ vs. $42 \%$, respectively) ( $p=0.283)$. Patients in group 1 and group 2 underwent total gastrectomy at a higher rate, with $79.2 \%$ and $60 \%$, respectively, whereas in group 3, subtotal gastrectomy was performed on $63.2 \%$ of the patients. The number of lymph nodes dissected was highest in group 1 ( 24.25 vs. 13.70 vs. 9.52, $p=0.00)$. The anastomosis leak $(p=0.285)$ and post-operative 90-day mortality ( $p=0.285)$ were similar in each group. Local recurrence was most frequent in group 1 ( $50 \%$ vs. $40 \%$ vs. $10.5 \%, p=0.023)$. Total survival time was shortest in group 1 (31 months vs. 78 months vs. 99 months, $p=0.005)$.

Conclusion: While demographic characteristics, clinical features, and surgical results were not affected by tumor histology, oncological results (overall survey and local recurrence) were associated with tumor histology. Undifferentiated carcinoma showed an oncologically aggressive course compared to other histological types.

Keywords: Gastric cancer, operative therapy histopathology, survival, post-operative complications

\section{INTRODUCTION}

Gastric cancer, with 989,600 new cases and 738,000 deaths per year worldwide, constitutes around eight percent of all cancers, making it one of the most common forms of the disease (1).
In 2015 statistics from Turkey, the incidence of gastric cancer in men was reported to be $14.2 / 100,000$, while in women it was reported to be $6.3 / 100000$. It was also reported as the second most common cause of cancer-related death in men and the fourth most common in women (2). 
There are various histopathological classification systems for the diagnosis of stomach cancer. The most detailed classification system is the histopathological classification system made by the World Health Organization (WHO) in 2010 and updated in 2019. Unlike other systems, the WHO classification includes all other types of low-frequency gastric tumors other than gastric adenocarcinoma $(3,4)$.

Undifferentiated gastric carcinoma is a rare neoplasm that does not show any differentiation from adenocarcinoma or squamous cell carcinoma (5). Various immunohistochemical stains are needed to exclude any differentiation. It should be distinguished from other neoplasms. As it is rare, the clinical behavior of undifferentiated gastric carcinoma has not been fully characterized yet, but it is thought to exhibit poor prognostic properties (6). Undifferentiated carcinoma is included in WHO classifications 4 and 5 , but details are not offered $(2,3)$.

Gastric neuroendocrine tumors are commonly referred to as carcinoids. They are tumors that arise from neuroendocrine cells within the enterochromaffin-like cells of the gastric mucosa (7).

Gastrointestinal stromal tumors are the most common mesenchymal tumors of the gastrointestinal tract and develop from interstitial Cajal cells in the intestinal wall (8).

Many variables on the outcome and prognosis of surgical treatment in stomach cancer have been discussed in the literature. It was determined that results were affected depending on numerous variables, such as tumor stage, tumor differentiation, applied surgical approach, hospital volume, surgeon volume, patient-related factors, age, immune status, and nutritional status (9-13).

Many studies have investigated the relationship between histopathological features and patient characteristics, diseasespecific criteria, and overall outcomes in gastric cancer (14-16). In the literature, however, there are limited comparative studies were limited on how surgical results will be affected, and how the different histological types will affect oncological results due to different tumor histology.

In this study, we discussed the surgical results and prognoses of undifferentiated carcinoma, neuroendocrine carcinoma, and stromal tumor, in our clinic. These are the less common histological types of gastric cancer, according to the literature.

\section{METHODS}

\section{Materials/Patients and Methods}

After the approval of the Ethics Committee of Erciyes University Faculty of Medicine dated 10.06.2020 and numbered 2020/270 fifty-three patients, out of the 1,060 patients who underwent curative surgery in our clinic between 2010 and 2019, who were diagnosed with undifferentiated carcinomas, neuroendocrine tumors, and gastrointestinal stromal tumors were included in the study. Mix tumors accompanied by this histological type, other histological subtypes, and patients undergoing palliative surgery were excluded from the study. The study was conducted in accordance with the ethical rules based on the principles of the Declaration of Helsinki.

Patient files, electronic records, pathology reports, surgery reports, anesthesia follow-up forms, and nurse observation forms were examined, and a common database was created prospectively. Patients were analyzed retrospectively using this database. The population registration system was used for survival analysis.

Patients were divided into three groups: Group 1 (undifferentiated tumor), group 2 (neuroendocrine tumor) and group 3 (gastrointestinal stromal tumor). The demographic and clinical features of the patients, body mass index (BMI), American Society of Anesthesiologists (ASA) score, blood parameters during hospitalization, tumor marker levels, tumor localizations, surgical procedure applied, additional organ resection, intraoperative complication status, duration of surgery, total number of lymph nodes dissected, number of metastatic lymph nodes, tumor size, presence of post-operative complications, anastomosis leak, oral-food onset time, hospital stay duration, post-operative 90day mortality, 90-day unplanned hospital re-admission, 90-day reoperation, local recurrence and systemic metastasis in the follow-up, and mean survival times were compared.

In all patients, distant metastases were scanned by thorax and abdominal computed tomography, and the diagnosis of malignancy was made because of pathological examination of the part taken by endoscopic biopsy. Histological subtypes were classified using WHO classifications (Figure 1-3) $(3,4,17)$.

Standard D2 lymph node dissection was performed in patients with undifferentiated carcinoma. The extent of lymph node dissection was determined according to the degree of neuroendocrine tumors. In stromal tumors, lymph node dissection was performed when lymph node positivity was shown. The patients were operated on using conventional techniques. Total gastrectomy, subtotal gastrectomy, and wedge resection were performed using the previously recognized and accepted techniques. The location and size of the tumor were effective in choosing the type of resection. 


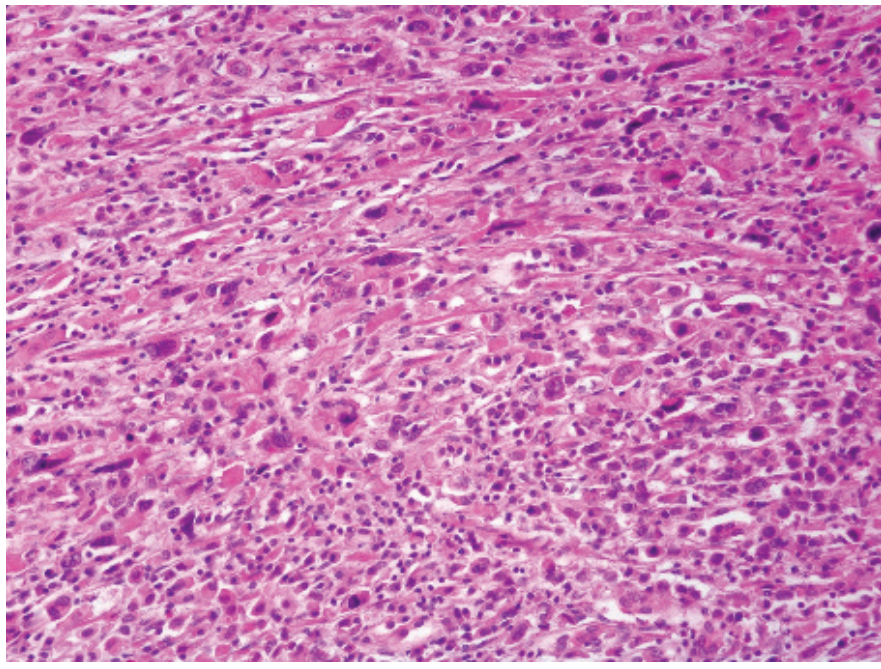

Figure 1. Undifferentiated carcinoma H\&E, X100 carcinoma cell infiltration with a high degree of atypia

H\&E: Hematoxylin and eosin

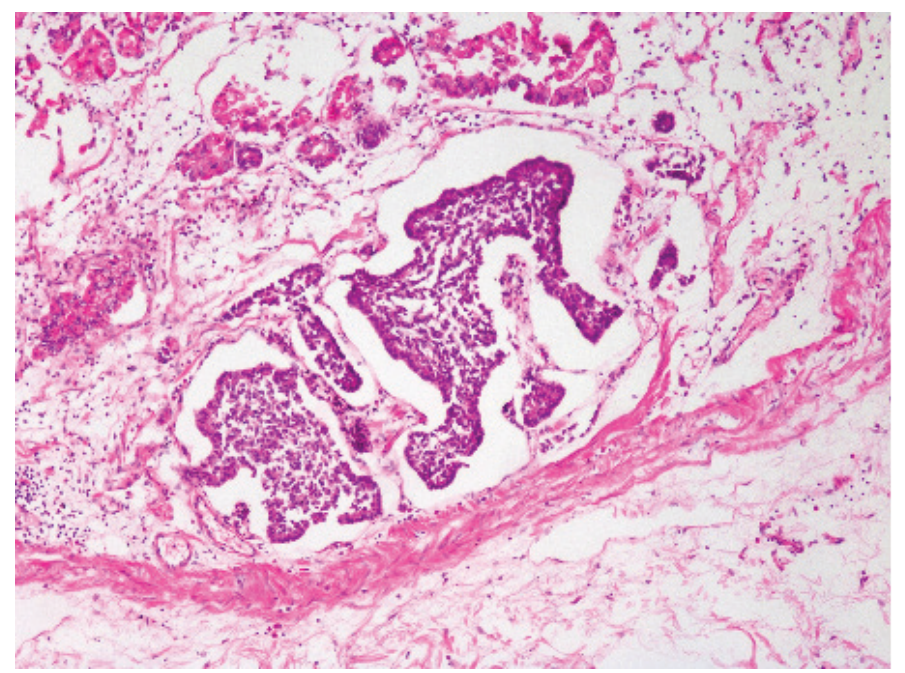

Figure 2. Neuroendocrine tumor $\mathrm{H \& E}, \mathrm{X} 40$ neuroendocrine tumor of the stomach, consisting of uniform cells within the mucosa H\&E: Hematoxylin and eosin

Anastomosis leak was defined as a disruption in the integrity of anastomosis, documented by a combination of clinical, radiological, and operative tools. Wound infection was defined as a superficial or deep incisional surgical-site infection occurring in the surgical wound, according to the definition of the centers for disease control (18).

Surgical quality was evaluated with markers post-operative 90day mortality such as 90-day re-admission and re-operation. Unplanned hospitalization within the first 90 days after discharge was considered an unplanned re-admission. We considered unplanned re-operation as a surgical procedure under general, spinal, or epidural anesthesia within 90 days of

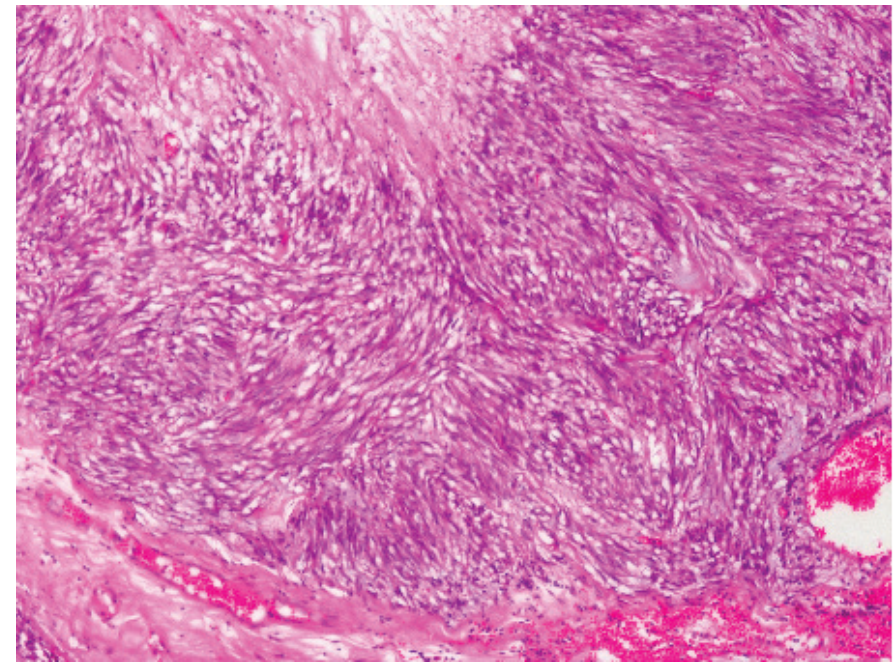

Figure 3. Gastrointestinal stromal tumor $\mathrm{H} \& \mathrm{E}, \mathrm{X} 40$ stomach gastro intestinal stromal tumor showing proliferation of spindle cells H\&E: Hematoxylin and eosin

the index operative procedure, for any reason other than followup procedures based on pathology results.

Oncological results were evaluated with parameters such as overall survival systematic metastasis and local recurrence.

The discharge criteria were similar in both groups, including meal tolerance without nausea or vomiting, adequate analgesia and pain control, and independent mobilization.

Total blood count was measured by an automated hematology analyzer

Roche Hitachi Cobas ${ }^{\circledR} 8000$ Roche Diagnostics, Indianapolis, IN, USA.

Since the study was retrospective, patient consent could not be obtained.

\section{Statistical Analysis}

The Statistical Package for the Social Sciences 23.0 program was used for the statistical analysis of data. Categorical measurements were summarized as numbers and percentages, while continuous measurements were summarized as mean and standard deviation (median and minimum-maximum, where necessary). Pearson's chi-square test statistics were used to compare categorical variables. The Shapiro-Wilk test was used to determine whether the parameters in the study showed a normal distribution. In comparing the continuous measurements between the groups, the distributions were checked and One-Way ANOVA was used for the parameters with normal distribution, and the Kruskal-Wallis test was used for parameters without normal distribution. Post-hoc analysis was used to determine the differences between the groups. Kaplan- 
Meier analysis and log rank tests were used in survival analyses. Statistical significance level was taken as 0.05 in all tests.

\section{RESULTS}

Fifty-three patients (5\%) from the 1,060 diseases were included in the study. Mean age of the patients ( $p=0.591)$, BMI ( $p=0.723$ ), and ASA scores $(p=0.559)$ were similar in the groups. Tumors were most frequently located in the corpus $(41.7 \%$ vs. $80 \%$ vs. $42 \%, p=0.283$ ). Demographic and clinical features were similar when the groups were compared in pairs. Demographic data of the patients are shown in Table 1.

There was no significant difference between the groups in terms of white blood cell counts $(p=0.355)$, neutrophil counts $(p=0.445)$, lymphocyte counts $(p=0.491)$, or albumin level $(p=0.112)$ parameters. Hemoglobin levels (12.90 vs. 12.84 vs. 10.84, $p=0.018$ ), carcinoembryonic antigen (CEA) levels (2.53 vs. 2.51 vs. 1.41) and CA 19.9 levels (44.90 vs. 8.92 vs. 10.2$)(p=0.001)$ were significantly different between the groups. The laboratory parameters of the patients are shown in Table 2.

Patients in groups 1 and 2 underwent total gastrectomy at a higher rate, with $79.2 \%$ and $60 \%$, respectively, whereas in group 3, subtotal gastrectomy was performed on $63.2 \%$ of the patients. All groups $(p=0.002)$ exhibited differences in terms of operation type. There was no statistical difference in terms of operation duration ( $215 \mathrm{~min}$ vs. $216 \mathrm{~min}$ vs. $208 \mathrm{~min}, \mathrm{p}=0.0448$ ). Additional organ resection was similar between the groups and was frequently performed ( $20.8 \%$ vs. $30 \%$ vs. $31.6 \%, p=0.701)$. No patient had intraoperative complications. The number of lymph nodes dissected was high in group 1 (24.25 vs. 13.70 vs. 9.52, $p=0.00)$. Between the groups it was seen as group 1-2 $(p=0.001)$ and group $1-3(p=0.000)$. The number of metastatic lymph nodes was highest in group 1 (11.50 vs. 70 vs. $0.36, p=0.000$ ). Between the groups it was seen as group 1-2 $(p=0.002)$ and group 1-3 $(p=0.000)$. Average tumor size was highest in group $3(5.57 \mathrm{~cm}$ vs. $4.26 \mathrm{~cm}$ vs $7.39 \mathrm{~cm}, p=0.048)$. Groups $3-1(p=0.050)$ exhibited this difference. These results are displayed in Table 3.

The onset of oral intake was latest in group 1 (5.04 days vs. 4.60 days vs. 4.15 days, $p=0.043$ ) (group 1-3, $p=0.033$ ). Anastomosis leak was seen only in two patients in group 1. Post-operative 90-day mortality was seen only in two patients in group 1 . Ninety-day re-admission rates were similar $(12.5 \%$ vs. $20 \%$ vs. $5.3 \%, p=0.478)$. In the post-operative period, one patient in group 1 underwent surgical intervention due to intra-abdominal hemorrhage. Local recurrence was more common in group 1 during follow-up ( $50 \%$ vs. $40 \%$ vs. $10.5 \%, p=0.0023$ ) (group $1-3$, $\mathrm{p}=0.007$ ). Systemic metastasis was most common in group 2 , with the most common location being the liver (40\%), and peritoneal carcinomatosis was most common in group 1 (20.8\%) (group $1-2 p=0.006$, group $2-3 p=0.040$ ). In the evaluation of current clinical status, the number of patients who died was highest in group $1(79.2 \%$ vs. $20 \%$ vs. $21.2 \%, p=0.00)$. Between the groups, the relationships were seen to be group $1-2(p=0.002)$ and group $1-3(p=0.00)$. This is shown in Table 4. Five-year overall survival was found as X\% in group 1, Y\% in group 2, and Z\% in group 3 .

Overall survival duration was significantly shorter in group 1 (31 vs. 78 vs. 99 months, $p=0.005)$. This is shown in both Table 5 and Graphic 1.

\begin{tabular}{|c|c|c|c|c|c|c|}
\hline \multirow{2}{*}{\multicolumn{2}{|c|}{ n (\%) }} & $\begin{array}{l}\text { Group } 1 \\
(n=24)\end{array}$ & $\begin{array}{l}\text { Group } 2 \\
(n=10)\end{array}$ & \begin{tabular}{|l|} 
Group 3 \\
$(n=19)$
\end{tabular} & \multirow[t]{2}{*}{$p$} & \multirow[t]{2}{*}{ Source of difference between groups } \\
\hline & & n (\%) & n (\%) & & & \\
\hline \multirow{2}{*}{$\operatorname{Sex}^{+}$} & Male & $16(66.7)$ & $5(50.0)$ & $12(63.2)$ & \multirow[t]{2}{*}{0.656} & \multirow{2}{*}{ No significant difference } \\
\hline & Female & $8(33.3)$ & $5(50.0)$ & $7(36.8)$ & & \\
\hline \multicolumn{2}{|l|}{ Age $(F)$} & $58.5 \pm 13.28$ & $56.3 \pm 13.03$ & $61.15 \pm 11.25$ & 0.591 & No significant difference \\
\hline \multirow{3}{*}{$\mathrm{ASA}^{+}$} & 1 & $16(66.7)$ & $4(40.0)$ & $12(63.2)$ & \multirow{3}{*}{0.559} & \multirow{3}{*}{ No significant difference } \\
\hline & 2 & $5(20.8)$ & $3(30.0)$ & $5(26.3)$ & & \\
\hline & 3 & $3(12.5)$ & $3(30.0)$ & $2(10.5)$ & & \\
\hline \multirow{3}{*}{ Location $^{+}$} & Antrum & $7(29.2)$ & $0(0.0)$ & $3(15.8)$ & \multirow{3}{*}{0.283} & \multirow{3}{*}{ No significant difference } \\
\hline & Large curvature & $1(4.2)$ & $1(10.0)$ & $0(0.0)$ & & \\
\hline & Small curvature & $3(12.5)$ & $1(10.0)$ & $5(26.3)$ & & \\
\hline
\end{tabular}




\begin{tabular}{|c|c|c|c|c|c|}
\hline & $\begin{array}{l}\text { Group } 1 \\
(n=24)\end{array}$ & $\begin{array}{l}\text { Group } 2 \\
(n=10)\end{array}$ & $\begin{array}{l}\text { Group } 3 \\
(n=19)\end{array}$ & \multirow[t]{2}{*}{$\mathbf{p}$} & \multirow[t]{2}{*}{ Source of difference between group } \\
\hline & Mean \pm SD & Mean \pm SD & Mean \pm SD & & \\
\hline WBC (F) & $8.42 \pm 2.57$ & $7.78 \pm 2.12$ & $9.22 \pm 2.94$ & 0.355 & No significant difference \\
\hline Neutrophil $\mathrm{mm}^{3}\left(\mathrm{x}^{2}\right)$ & $6.57 \pm 4.34$ & $5.04 \pm 1.70$ & $6.68 \pm 2.97$ & 0.445 & No significant difference \\
\hline Lymphocyte $\mathrm{mm}^{3}(\mathrm{~F})$ & $1.68 \pm 0.65$ & $1.97 \pm 0.60$ & $1.72 \pm 0.70$ & 0.491 & No significant difference \\
\hline $\mathrm{Hgb} \operatorname{gr} / \mathrm{dL}(\mathrm{F})$ & $12.90 \pm 2.71$ & $12.84 \pm 1.57$ & $10.84 \pm 2.36$ & 0.018 & 1-3: $p=0.021$ \\
\hline Albumin gr/dL $\left(x^{2}\right)$ & $3.76 \pm 0.75$ & $4.20 \pm 0.34$ & $3.67 \pm 0.64$ & 0.112 & No significant difference \\
\hline Pre-op CEA $\left(x^{2}\right)$ & $2.53 \pm 1.80$ & $2.51 \pm 1.00$ & $1.41 \pm 1.08$ & 0.036 & 1-3: $p=0.041$ \\
\hline Pre-op CA19-9 $\left(x^{2}\right)$ & $44.04 \pm 9.10$ & $8.92 \pm 5.75$ & $10.2 \pm 7.30$ & 0.001 & $\begin{array}{l}1-2: p=0.010 \\
1-3: p=0.002\end{array}$ \\
\hline
\end{tabular}

\begin{tabular}{|c|c|c|c|c|c|c|}
\hline \multicolumn{2}{|l|}{ n (\%) } & $\begin{array}{l}\text { Group } 1 \\
(n=24)\end{array}$ & $\begin{array}{l}\text { Group } 2 \\
(n=10)\end{array}$ & $\begin{array}{l}\text { Group } 3 \\
(n=19)\end{array}$ & $\mathbf{p}$ & $\begin{array}{l}\text { Source of difference } \\
\text { between groups }\end{array}$ \\
\hline \multirow[b]{2}{*}{ Type of operation ${ }^{+}$} & Subtotal & $5(20.8)$ & $4(40.0)$ & $12(63.2)$ & \multirow[b]{2}{*}{0.009} & \multirow[b]{2}{*}{ 1-3: $p=0.002$} \\
\hline & Total & $19(79.2)$ & $6(60.0)$ & $5(26.3)$ & & \\
\hline \multirow{2}{*}{$\begin{array}{l}\text { Additional organ } \\
\text { resection }\end{array}$} & No & $19(79.2)$ & $7(70.0)$ & $13(68.4)$ & \multirow{2}{*}{0.701} & \multirow{2}{*}{$\begin{array}{l}\text { No significant } \\
\text { difference }\end{array}$} \\
\hline & Yes & $5(20.8)$ & $3(30.0)$ & $6(31.6)$ & & \\
\hline \multirow{5}{*}{$\begin{array}{l}\text { Additional organ } \\
\text { resection }^{+}\end{array}$} & Spleen & $2(8.3)$ & $0(0.0)$ & $1(5.3)$ & \multirow{5}{*}{0.247} & \multirow{5}{*}{$\begin{array}{l}\text { No significant } \\
\text { difference }\end{array}$} \\
\hline & Colon and liver & $0(0.0)$ & $2(20.0)$ & $0(0.0)$ & & \\
\hline & Gallbladder & $1(4.2)$ & $0(0.0)$ & $1(5.3)$ & & \\
\hline & Gallbladder and spleen & $1(4.2)$ & $1(10.0)$ & $1(5.3)$ & & \\
\hline & No & $19(79.2)$ & $7(70.0)$ & $13(68,4)$ & & \\
\hline \multirow{2}{*}{$\begin{array}{l}\text { Intraoperative } \\
\text { complication }^{+}\end{array}$} & None & $24(100.0)$ & $10(100.0)$ & $19(100.0)$ & \multirow{2}{*}{1.000} & \multirow{2}{*}{$\begin{array}{l}\text { No significant } \\
\text { difference }\end{array}$} \\
\hline & Present & $0(0.0)$ & $0(0.0)$ & $0(0.0)$ & & \\
\hline \multicolumn{2}{|l|}{ Total lymph node (F) } & $24.25 \pm 8.14$ & $13.70 \pm 8.42$ & $9.52 \pm 6.06$ & 0.000 & $\begin{array}{l}1-2: p=0.001 \\
1-3: p=0.000\end{array}$ \\
\hline \multicolumn{2}{|c|}{ Metastatic lymph node $\left(\mathrm{x}^{2}\right)$} & $11.50 \pm 10.11$ & $1.70 \pm 2.83$ & $0.36 \pm 1.60$ & 0.000 & $\begin{array}{l}1-2: p=0.002 \\
1-3: p=0.000\end{array}$ \\
\hline
\end{tabular}

\section{DISCUSSION}

Historically, gastric carcinomas have been classified into two histological types through standard hematoxylin and eosin staining. Lauren classified them as "intestinal" type and "diffuse" type, while "differentiated" type and "undifferentiated" type where the classifications presented by Nakamura et al. $(19,20)$.
In the WHO histological classifications, gastric cancers are divided into many histological subtypes and subtypes within these subtypes $(3,4)$.

Although the prognosis of resectable gastric cancer clearly depends on the pathological stage of the disease, controversy still surrounds the prognostic value of the histological type. The 


\begin{tabular}{|c|c|c|c|c|c|c|}
\hline \multirow{2}{*}{\multicolumn{2}{|c|}{ n (\%) }} & $\begin{array}{l}\text { Group } 1 \\
(n=24)\end{array}$ & $\begin{array}{l}\text { Group } 2 \\
(n=10)\end{array}$ & $\begin{array}{l}\text { Group } 3 \\
(n=19)\end{array}$ & \multirow[t]{2}{*}{$p$} & \multirow{2}{*}{$\begin{array}{l}\text { Source of } \\
\text { difference } \\
\text { between group }\end{array}$} \\
\hline & & n (\%) & $n(\%)$ & & & \\
\hline \multicolumn{2}{|l|}{ Onset of oral intake (day) $\left(x^{2}\right)$} & $5.04 \pm 1.36$ & $4.60 \pm 1.07$ & $4.15 \pm 0.68$ & $0.043^{*}$ & 1-3: $p=0.033$ \\
\hline \multicolumn{2}{|c|}{ Hospitalization duration (day) $\left(x^{2}\right)$} & $11.66 \pm 4.92$ & $12.20 \pm 3.61$ & $11.78 \pm 5.10$ & 0.957 & $\begin{array}{l}\text { No significant } \\
\text { difference }\end{array}$ \\
\hline \multirow{2}{*}{ Anastomosis leakage $^{+}$} & No & $22(91.7)$ & $10(100.0)$ & $19(100.0)$ & \multirow{2}{*}{0.285} & \multirow{2}{*}{$\begin{array}{l}\text { No significant } \\
\text { difference }\end{array}$} \\
\hline & Yes & $2(8.3)$ & $0(0.0)$ & $0(0.0)$ & & \\
\hline \multirow{2}{*}{ Post-op 90-day mortality ${ }^{+}$} & No & $22(91.7)$ & $10(100.0)$ & $19(100.0)$ & \multirow{2}{*}{0.285} & \multirow{2}{*}{$\begin{array}{l}\text { No significant } \\
\text { difference }\end{array}$} \\
\hline & Yes & $2(8.3)$ & $0(0.0)$ & $0(0.0)$ & & \\
\hline \multirow{2}{*}{ 90-day readmission ${ }^{+}$} & No & $21(87.5)$ & $8(80.0)$ & $18(94.7)$ & \multirow{2}{*}{0.478} & \multirow{2}{*}{$\begin{array}{l}\text { No significant } \\
\text { difference }\end{array}$} \\
\hline & Yes & $3(12.5)$ & $2(20.0)$ & $1(5.3)$ & & \\
\hline \multirow{4}{*}{ 90-day readmission ${ }^{+}$} & Ileus & $0(0.0)$ & $1(10.0)$ & $0(0.0)$ & \multirow{4}{*}{0.352} & \multirow{4}{*}{$\begin{array}{l}\text { No significant } \\
\text { difference }\end{array}$} \\
\hline & Oral intake disorder & $2(8.3)$ & $1(10.0)$ & $0(0.0)$ & & \\
\hline & Wound site infection & $1(4.2)$ & $0(0.0)$ & $1(5.3)$ & & \\
\hline & No & $21(87.5)$ & $8(80.0)$ & $18(94.7)$ & & \\
\hline \multirow{2}{*}{ 90-day reoperation ${ }^{+}$} & No & $23(95.8)$ & $10(100.0)$ & $19(100.0)$ & \multirow{2}{*}{0.540} & \multirow{2}{*}{$\begin{array}{l}\text { No significant } \\
\text { difference }\end{array}$} \\
\hline & Yes & $1(4.2)$ & $0(0.0)$ & $0(0.0)$ & & \\
\hline \multirow{2}{*}{ Local recurrence $^{+}$} & No & $12(50.0)$ & $6(60.0)$ & 17 (89.5) & \multirow{2}{*}{0.023} & \multirow{2}{*}{ 1-3: $p=0.007$} \\
\hline & Yes & $12(50.0)$ & $4(40.0)$ & $2(10.5)$ & & \\
\hline \multirow{2}{*}{ Systematic metastasis ${ }^{+}$} & No & $18(75.0)$ & $6(60.0)$ & 15 (78.9) & \multirow{2}{*}{0.534} & \multirow{2}{*}{$\begin{array}{l}\text { No significant } \\
\text { difference }\end{array}$} \\
\hline & Yes & $6(25.0)$ & $4(40.0)$ & $4(21.1)$ & & \\
\hline \multirow{5}{*}{ Systematic metastasis ${ }^{+}$} & Brain & $1(4.2)$ & $0(0.0)$ & $1(5.3)$ & \multirow{5}{*}{0.004} & \multirow{5}{*}{$\begin{array}{l}1-2: p=0.006 \\
2-3: p=0.040\end{array}$} \\
\hline & Liver & $0(0.0)$ & $4(40.0)$ & $0(0.0)$ & & \\
\hline & Esophagus & $0(0.0)$ & $0(0.0)$ & $1(5.3)$ & & \\
\hline & Peritoneum & $5(20.8)$ & $0(0.0)$ & $2(10.5)$ & & \\
\hline & No & $18(75.0)$ & $6(60.0)$ & $15(78.9)$ & & \\
\hline \multirow{2}{*}{ Current status $^{+}$} & Ex & $19(79.2)$ & $2(20.0)$ & $4(21.1)$ & \multirow{2}{*}{0.000} & 1-2: $p=0.002$ \\
\hline & Alive & $5(20.8)$ & $8(80.0)$ & 15 (78.9) & & $1-3: p=0.000$ \\
\hline
\end{tabular}

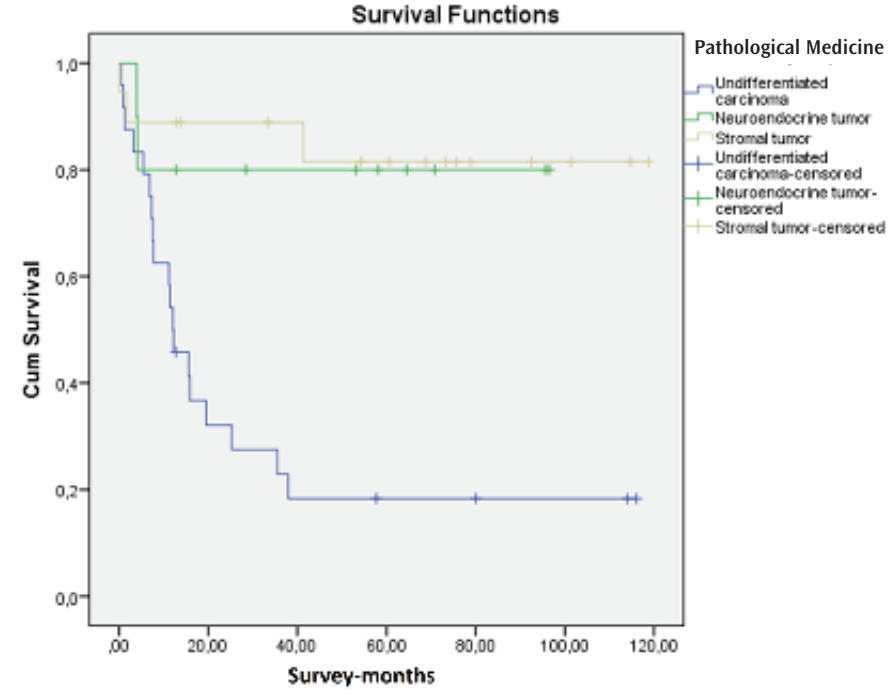

Graphic 1. Overall survival in terms of the histologic type

\begin{tabular}{|l|l|l|}
\hline \multicolumn{3}{|l|}{ Table 5. Mean survival duration by groups } \\
\cline { 1 - 2 } Group & Average [mean + SD (minimum-maximum)] & $\mathbf{p}$ \\
\hline 1 & $31.79 \pm 8.61(14.91-48.68)$ & \multirow{2}{*}{$\mathbf{0 . 0 0 5 *}$} \\
\hline 2 & $78.05 \pm 11.70(55.11-100.99)$ & \\
\hline 3 & $99.86 \pm 9.90(80.44-119.28)$ & \\
\hline${ }^{*} p<0.05$, SD: Standard deviation & \\
\hline
\end{tabular}

histological type appears to be an important clinical parameter for tumors. Additionally, histological type has been proposed as an important factor in evaluating the prognosis of the patient (21). Research on the prognosis of the WHO histological classification is increasingly prevalent. Zu et al. (22) highlighted significant differences in clinical and tumor characteristics of different histological subtypes of advanced gastric cancer. 
Tumor markers are often used to determine the prognosis of cancer patients after radical surgery, but the role of tumor markers in stomach cancer is still controversial. Since high-serum tumor markers are often associated with tumor progression, most of the previous reports have found pre-operative high serum markers to be significantly associated with long-term poor patient survival $(23,24)$. The relationship between serum tumor marker levels and tumor histology is also controversial. In a study by Mattar et al. (25) no correlation was found between serum tumor marker levels and the histology of the tumor. The study of Ishigami et al. (26) displayed the lowest positivity rate of tumor markers in patients with undifferentiated tumors, when they grouped patients as "differentiated" and "undifferentiated". In our series, CEA levels were higher in undifferentiated carcinoma, and oncological results were worse in this group.

Stromal tumors are slow-progressing tumors by nature and may not cause symptoms until they reach large sizes. Large tumors can often cause gastrointestinal bleeding (8). Neuroendocrine tumors are tumors that show the hormonal activity and show these activities even with a small tumor diameter. Considering the increasing rates of endoscopy, they can be detected even in small tumor sizes (8). We linked the difference in tumor diameters in our study to these tumors. With stromal tumors, low hemoglobin was noted due to the frequent gastrointestinal bleeding they cause.

The lymphatic metastasis rates of stromal tumors are low. They spread hematogenously and through adjacency. Therefore, lymphadenectomy is not routinely recommended (8). In contrast, differentiated tumors frequently exhibit lymph node metastasis and are aggressive by nature (6). Regarding lymphadenectomy for neuroendocrine tumors, it is recommended if there is extra gastric involvement or poor prognostic factors (as with type 3 gastric neuroendocrine tumors) (7). In our series, we decided on the width of lymphadenectomy by considering recommendations from the literature. Similar to findings in the literature, lymph node positivity was low in stromal tumors. In contrast, undifferentiated tumors showed a high rate of lymph node involvement.

Despite the recent decrease in the incidence of anastomosis leakage due to the increased awareness of surgical techniques, risk factors, and treatment options, it remains the most feared complication and is reported in the literature to range from $2.1 \%$ to $14.6 \%$ (27). Risk factors previously reported include the patient's tumor characteristics and intraoperative factors $(28,29)$. In our series, anastomosis leakage developed in two patients in the undifferentiated group, and tumor types were not associated with this.
Following surgery, reoperation is associated with morbidity, mortality, and increased health-care system costs, and is a potentially sensitive surgical quality marker $(30,31)$. The patient's re-admission after discharge from the hospital disrupts the predicted course of post-operative recovery and is a concern for the patient and their family. Additionally, it increases costs, causes labor loss and hinders the effective usage of hospital beds. Unplanned re-applications and re-operations may lead to delays in chemotherapy programs and oncological outcomes. Therefore, it is important to uncover the related factors. The need for unplanned re-operation after surgery generally manages some rare, serious, or life-threatening post-operative complications, following gastrectomy, and has rarely been reported. In the literature, many parameters related to the patient, surgical method, and tumor have been evaluated for post-operative mortality, re-operation, and re-admission (23-34). Yalav and Topal (34) found the adenocarcinoma histology as a risk factor for post-operative mortality in their study investigating the relationship between tumor histology and post-operative mortality.

In our series, tumor histology was not directly related to surgical quality. As expected, our most common reasons for application after discharge were wound problems and impaired oral food intake. There were two patients who developed post-operative mortality. The cause of mortality had cardiac origin in one patient and sepsis, due to anastomosis leak, in the other.

In the literature, studies on undifferentiated gastric carcinoma are in the form of case series, and there are no broad-based studies. In the series of Endo et al. (6) tumors were detected at an advanced stage and followed an aggressive course. Average survival were between three and seven months. Similar to other cases in the literature, these cases were associated with lower survival and an increased risk of metastasis $(35,36)$. In our series, local recurrence was detected in half of the patients in undifferentiated carcinoma. Peritoneal carcinomatosis developed in five of our patients, and $80 \%$ of these patients died during their follow-up. Mean survival was very low in this group compared with other groups. Undifferentiated tumors were more aggressive than other histological subtypes.

\section{Study Limitations}

The most significant limitation of our study was that it was retrospective and the number of patients was low. Considering the low incidence of these tumors, and the limited number of studies in the literature on the comparison of results relating to them, we believe that our study contributes to the body of research. 


\section{CONCLUSION}

While demographic and clinical features and operation results were not affected by tumor type, oncological results (overall survival, systematic metastasis, and local recurrence) were generally closely related to tumor type. A multidisciplinary approach that includes endoscopist, pathologist, radiologist, medical oncologist, and surgical team is required for optimal management of stomach cancer. The prognosis of patients cannot be considered independent of the histological type of tumor. Identification of tumors with aggressive biological characteristics will guide us in the management of patients. Even if the demographic, clinical, and surgical quality results of the cases were similar, the tumor histological type directly related to patient prognosis.

\section{Ethics}

Ethics Committee Approval: Approval was obtained with the decision of Erciyes University Faculty of Medicine Ethics Committee dated 10.06.2020 and numbered 2020/270.

Informed Consent: Retrospective study.

Peer-review: Externally and internally peer-reviewed.

\section{Authorship Contributions}

Surgical and Medical Practices: U.T., F.D., E.M.S., M.A., Ș.Y.I., M.G., K.D., Concept: U.T., F.D., E.M.S., M.A., M.G., K.D., Design: U.T., F.D., E.M.S., M.A., M.G., K.D., Data Collection or Processing: M.A., Ş.Y.i.., K.D., Analysis or Interpretation: F.D., E.M.S., Literature Search: U.T., F.D., Ş.Y.I., Writing: U.T., F.D., M.A.

Conflict of Interest: No conflict of interest was declared by the authors.

Financial Disclosure: The authors declared that this study received no financial support.

\section{REFERENCES}

1. Jemal A, Bray F, Center MM, Ferlay J, Ward E, Forman D. Global cancer statistics. CA Cancer J Clin 2011;61:69-90. Erratum in: CA Cancer J Clin 2011;61:134.

2. 2-Türkiye'de Kanser istatistikleri. Available at: https://hsgm.saglik.gov.tr/ depo/birimler/kanser-db/istatistik/Turkiye_Kanser_Istatistikleri_2015. pdf acces date 15.04.2020

3. Lauwers GY, Carneiro F, Graham DY, Curado MP. Gastric Carcinoma. In: Bosman FT, Carneiro F, Hruban RH, Theise ND, eds. WHO Classification of Tumours of the Digestive System. IARC, Lyon; 2010.p.48-58.

4. Nagtegaal ID, Odze RD, Klimstra D, Paradis V, Rugge M, Schirmacher P, et al. The 2019 WHO classification of tumours of the digestive system. Histopathology 2020;76:182-8.

5. Japanese Gastric Cancer Association. Japanese classification of gastric carcinoma: 3rd English edition. Gastric Cancer 2011;14:101-12.
6. Endo S, Nishikawa K, Yamada T, Nakagawa T, Fushimi H, Chihara T, et al. Our experience of treating undifferentiated gastric carcinoma: report of four cases. Surg Today 2015;45:235-40.

7. Corey B, Chen H. Neuroendocrine tumors of the stomach. Surg Clin North Am 2017;97:333-43.

8. Gupta SK, Rateria N. Gastrointestinal stromal tumors (GIST): an overview. Indian J Surg 2020;83:647-53.

9. Yalav 0 , Topal U, Unal AG. Clinical value of neutrophil/lymphocyte ratio in predicting postoperative complications, lymph node positivity and prognosis in gastric cancer patients who underwent curative surgical resection. Ann Med Res 2019;26:2513-9.

10. Iwatsuki M, Yamamoto H, Miyata H, Kakeji Y, Yoshida K, Konno H, et al. Effect of hospital and surgeon volume on postoperative outcomes after distal gastrectomy for gastric cancer based on data from 145,523 Japanese patients collected from a nationwide web-based data entry system. Gastric Cancer 2019;22:190-201.

11. Claassen YHM, van Amelsfoort RM, Hartgrink HH, Dikken JL, de Steur WO, van Sandick JW, et al. Effect of hospital volume with respect to performing gastric cancer resection on recurrence and survival: results from the CRITICS trial. Ann Surg 2019;270:1096-102.

12. Orman S, Cayci HM. Gastric cancer: factors affecting survival. Acta Chir Belg 2019;119:24-30.

13. Lee HJ, Hyung WJ, Yang HK, Han SU, Park YK, An JY, et al. Short-term outcomes of a multicenter randomized controlled trial comparing laparoscopic distal gastrectomy with D2 lymphadenectomy to open distal gastrectomy for locally advanced gastric cancer (KLASS-02-RCT). Ann Surg 2019;270:983-91.

14. Zheng HC, Zheng YS, Xia P, Xu XY, Xing YN, Takahashi H, et al. The pathobiological behaviors and prognosis associated with Japanese gastric adenocarcinomas of pure WHO histological subtypes. Histol Histopathol 2010;25:445-52.

15. Su JS, Chen YT, Wang RC, Wu CY, Lee SW, Lee TY. Clinicopathological characteristics in the differential diagnosis of hepatoid adenocarcinoma: a literature review. World J Gastroenterol 2013;19:321-7.

16. Berlth F, Bollschweiler E, Drebber U, Hoelscher AH, Moenig S. Pathohistological classification systems in gastric cancer: diagnostic relevance and prognostic value. World J Gastroenterol 2014;20:5679-84.

17. Hamilton SR, Aaltonen LA. Pathology and genetics of tumours of the digestive system b2000 (volume 2). Lyon: IARC press.

18. Horan TC, Gaynes RP, Martone WJ, Jarvis WR, Emori TG. CDC definitions of nosocomial surgical site infections, 1992: a modification of CDC definitions of surgical wound infections. Infect Control Hosp Epidemiol 1992;13:606-8

19. Lauren P. The two histological main types of gastric carcinoma: diffuse and so-called intestinal-type carcinoma. Acta Pathol Microbiol Scand 1965;64:31-49.

20. Nakamura K, Sugano H, Takagi K. Carcinoma of the stomach in incipient phase: its histogenesis and histological appearances. Gan 1968;59:2518.

21. Park JM, Jang YJ, Kim JH, Park SS, Park SH, Kim SJ, et al. Gastric cancer histology: clinicopathologic characteristics and prognostic value. J Surg Oncol 2008;98:520-5.

22. Zu H, Wang H, Li C, Xue Y. Clinicopathologic characteristics and prognostic value of various histological types in advanced gastric cancer. Int J Clin Exp Pathol 2014;7:5692-700.

23. Huang ZB, Zhou X, Xu J, Du YP, Zhu W, Wang J, et al. Prognostic value of preoperative serum tumor markers in gastric cancer. World J Clin Oncol 2014;5:170-6. 
24. Shimada H, Noie T, Ohashi M, Oba K, Takahashi Y. Clinical significance of serum tumor markers for gastric cancer: a systematic review of literature by the Task Force of the Japanese Gastric Cancer Association. Gastric Cancer 2014;17:26-33.

25. Mattar R, Alves de Andrade CR, DiFavero GM, Gama-Rodrigues JJ, Laudanna AA. Preoperative serum levels of CA 72-4, CEA, CA 19-9, and alpha-fetoprotein in patients with gastric cancer. Rev Hosp Clin Fac Med Sao Paulo 2002;57:89-92.

26. Ishigami S, Natsugoe S, Hokita S, Che X, Tokuda K, Nakajo A, et al. Clinical importance of preoperative carcinoembryonic antigen and carbohydrate antigen 19-9 levels in gastric cancer. J Clin Gastroenterol 2001;32:41-4.

27. Makuuchi R, Irino T, Tanizawa Y, Bando E, Kawamura T, Terashima M. Esophagojejunal anastomotic leakage following gastrectomy for gastric cancer. Surg Today 2019;49:187-96.

28. Russell MC, Mansfield PF. Surgical approaches to gastric cancer. J Surg Oncol 2013;107:250-8.

29. Yalav 0, Topal U. Risk factors for leakage after total gastrectomy. Ann Med Res 2020;27:174-80.

30. Tsai TC, Joynt KE, Orav EJ, Gawande AA, Jha AK. Variation in surgicalreadmission rates and quality of hospital care. N Engl J Med 2013;369:1134-42.
31. Merkow RP, Bilimoria KY, Cohen ME, Richards K, Ko CY, Hall BL. Variability in reoperation rates at 182 hospitals: a potential target for quality improvement. J Am Coll Surg 2009;209:557-64.

32. Li SS, Costantino CL, Mullen JT. Morbidity and mortality of total gastrectomy: a comprehensive analysis of 90-day outcomes. J Gastrointest Surg 2019;23:1340-8.

33. Xiao H, Wang Y, Quan H, Ouyang Y. Incidence, causes and risk factors for 30-day unplanned reoperation after gastrectomy for gastric cancer: experience of a high-volume center. Gastroenterology Res 2018;11:21320.

34. Yalav 0, Topal U. Predictive factors associated mortality after gastrectomy. Ann Med Res 2020;27:326-33.

35. Ueda K, Yamazoe S, Kawazoe Y, Iwasaki Y, Naka T, Yamaue $\mathrm{H}$, et al. Perforated undifferentiated gastric cancer with metastaticsmall intestinal tumors: a case report (in Japanese with English abstract). J Abdom Emerg Med 2010;30:937-40.

36. Yamamoto M, Kobayashi Y, Ochiai M, Terasawa H, MizumotoY, Tsubota Y. A rapidly progressed case of undifferentiated gastric cancer (in Japanese with English abstract). J Jpn Surg Assoc 2012;73:2841-46. https://www. jstage.jst.go.jp/article/jjsa/73/11/73_2841/_pdf/-char/en 